\title{
Investigation of the Central, Peripheral Analgesic and Anti- inflammatory Activity of Kutajarishta, an Indian Ayurvedic formulation.
}

\author{
Ninadh Malrina D’Costa ${ }^{1}$, Mehdi Bin Samad ${ }^{2}$, Ashraf-ul Kabir ${ }^{3}$, \\ Prof. Dr. JMA Hannan ${ }^{4}$. \\ 1,2,3,4 Department of Pharmacy, North South University, Dhaka, Bangladesh
}

\begin{abstract}
Kutajarishta (KTJ) is an Ayurvedic formulation approved by the "National formulary of Ayurvedic Medicine 2011", of Bangladesh. It is widely available in the Bangladeshi market as an effective preparation to treat lumbago, sciatia and arthritic pain of joints. Our present studies make an attempt toward identifying probable anti-nociceptive and anti-inflammatory mechanisms of KTJ. KTJ, at three doses, $(10 \mathrm{~mL} / \mathrm{kg}, 20 \mathrm{~mL} / \mathrm{kg}$, and $40 \mathrm{~mL} / \mathrm{kg}$ ) showed no involvement of the CNS in anti-nociceptive activity in Hot plate test and Tail immersion test models. Carrageenan induced paw edema and acetic acid writhing tests both gave significant results $(P \leq 0.05)$, indicating possible peripheral analgesic and anti-inflammatory action. Formalin induced paw-licking test showed that KTJ had significant effect in suppressing inflammatory pain $(P \leq 0.05)$ but not neurogenic pain. Hence our study shows anti-inflammatory and peripheral analgesic action for KTJ.
\end{abstract}

Keywords: Anti-inflammatory, anti-nociceptive, central analgesic, kutajarishta, peripheral analgesic

\section{Introduction}

World health Organization (WHO) has stated that up to $80 \%$ of the population in many Asian and African countries depend on traditional and complimentary drugs to meet their medical necessities ${ }^{[1]}$. It is also an extremely attractive business for many drug vendors which often results in misleading claims being made and confusion in the mind of consumers. Persistent continuation of a regimen with one of these drugs which do not have any pharmacological activity, in reality, would seriously aggravate the morbidity of the patients. For these reasons and others, there has been a demand for ensuring the safety and efficacy of some of these traditional/herbal medicines ${ }^{[2]}$. Under the status quo, these products are often sold under hyperbolic and outrageous claims without much scientific evidences ${ }^{[3]}$. In this paper, we analyzed the analgesic and antiinflammatory property of Kutajarishta (KTJ), a commonly available herbal product licensed under the Directorate General of Drug Administration (DGDA) of Bangladesh.

Pain has been defined by The International Association for the Study of Pain as an unpleasant sensory and emotional experience associated with actual or potential tissue damage ${ }^{[4]}$. This process enables an individual to take protective measures, by providing with rapid awareness about threatening or potentially threatening injury ${ }^{[5]}$. However, if the painful sensation remains after removal of the detectable stimulus, it calls for a regimen for pain management ${ }^{[6]}$.

Kutajarishta (KTJ) is included in the Bangladesh National Formulary of Ayurvedic Medicine $2011\left(2^{\text {nd }}\right.$ Ed.) ${ }^{[7]}$. It is primarily indicated in rheumatoid arthritis, lumbago (low-back pain) and sciatica (pain which may arise from compression and/or irritation of one of five spinal nerve roots which give rise to each sciatic nerve) [7]. The present study was undertaken to evaluate the potential analgesic and anti-inflammatory activity of the Kutajarishta (KTJ) and the probable mechanism behind the activity.

\section{Materials And Method}

\subsection{Reagents Used:}

All reagents and chemicals that were used in the experiments were of analytical grade. KTJ was procured from University Ayurvedic Research Centre, Jahangirnagar University, Savar, Bangladesh. Pharmaceutical grade tramadol, and diclofenac sodium were collected from Square Pharmaceuticals Bangladesh Ltd. All other reagents were procured from Sigma Aldrich (USA) unless mentioned otherwise.

\subsection{Dose and Route of Administration:}

$0.9 \% \mathrm{NaCl}$ was administered to the animals per oral (p.o.) at a volume that would not cause any additional psychological or physiological stress to the animals. For experimental purpose $10 \mathrm{~mL} / \mathrm{kg}, 20 \mathrm{~mL} / \mathrm{kg}$, and $40 \mathrm{~mL} / \mathrm{kg}$ doses of KTJ were used since, the drug proved to be non-lethal at all doses that were administered. 


\subsection{Maintainence and use of test animals:}

Healthy Swiss Albino mice (5-6 weeks old, of both sex) weighing 20-25g and Spraugue-Dawley rats, weighing 130-160g, were procured from Jahangir Nagar University Animal House. The test subjects were provided with standard rat pellet diet and filtered drinking water ad libitum. This study was approved by an ethics committee of North South University (Approval no: LSAEC-21F-2012) which gave its consent in absolute accordance with the recommendations of the international Association for the study of Pain ${ }^{[8]}$.

\subsection{Grouping and Drug administration:}

The animals were randomly divided into several groups of 8 mice/rats for the planned analgesic and anti-inflammatory tests. Control groups were treated p.o. with $0.9 \% \mathrm{NaCl}$. Positive controls were treated with tramadol and diclofenac sodium. Treatment groups were treated with three doses $(10 \mathrm{~mL} / \mathrm{kg}, 20 \mathrm{~mL} / \mathrm{kg}$, and $40 \mathrm{~mL} / \mathrm{kg}$ ) of KTJ.

\subsection{Determination of CNS Modulation in Analgesic Activity \\ 2.5.1. Hot Plate Test:}

The Hot plate test was performed on the test subjects in a slightly modified version from the one described earlier ${ }^{[9]}$. The animals were placed on hot plate apparatus (Model-35100, manufacturer-UGO Basile of Italy) maintained at a temperature of $54 \pm 0.5^{\circ} \mathrm{C}$ for a maximum time of $20 \mathrm{~s}$ per exposure. The control group was administered with $0.9 \% \mathrm{NaCl}$ p.o. The treatment groups were treated with $\mathrm{KTJ}(10 \mathrm{~mL} / \mathrm{kg}, 20 \mathrm{~mL} / \mathrm{kg}$, and $40 \mathrm{~mL} / \mathrm{kg}$ p.o.). Naloxone (5mg/kg i.p.) was administered with KTJ (10mL/kg, $20 \mathrm{~mL} / \mathrm{kg}$, and $40 \mathrm{~mL} / \mathrm{kg} \mathrm{p.o.)} \mathrm{and}$ Tramadol (p.o.) to four different groups, other than the treatment groups.

\subsubsection{Tail Immersion test:}

The tail immersion test was performed according to the procedures used by Wang et al. ${ }^{[10]}$, with minor modifications. Briefly, the lower two-third of mouse's tail was immersed in a constant temperature water bath at $50 \pm 0.2^{\circ} \mathrm{C}$. The reaction time, i.e. the amount of time it takes the animal to withdraw its tail was measured. KTJ $(10 \mathrm{~mL} / \mathrm{kg}, 20 \mathrm{~mL} / \mathrm{kg}$, and $40 \mathrm{~mL} / \mathrm{kg}$ p.o.), tramadol $(10 \mathrm{mg} / \mathrm{Kg}$ p.o.), and $0.9 \% \mathrm{NaCl}$ (p.o.) were administered to treatment groups. Naloxone (5mg/kg i.p.) was administered with KTJ (10mL/kg, $20 \mathrm{~mL} / \mathrm{kg}$, and $40 \mathrm{~mL} / \mathrm{kg}$ p.o.) and tramadol to four different groups, other than the treatment groups.

\subsection{Determination of Peripheral Analgesia}

\subsubsection{Acetic-acid induced writhing test:}

The test was carried out using a modified method from the procedure perviously described ${ }^{[11]}$. KTJ at three doses $(10 \mathrm{~mL} / \mathrm{kg}, 20 \mathrm{~mL} / \mathrm{kg}$, and $40 \mathrm{~mL} / \mathrm{kg}$ p.o.) were administered to treatment groups. Positive control group was administered with diclofenac sodium $(10 \mathrm{mg} / \mathrm{kg}$ p.o.) and $0.9 \% \mathrm{NaCl}$ p.o. was administered to the control group. 45 minutes after drug treatment, the mice were given $0.7 \% \mathrm{v} / \mathrm{v}$ acetic acid $(0.15 \mathrm{~mL} / 10 \mathrm{~mL}$ i.p. $)$ to induce writhing.

\subsubsection{Carrageenan induced Paw Edema test:}

Carrageenan induced paw edema test was carried out by following the method described previously ${ }^{[12]}$. Male and female Spraugue-Dawley rats were used. The control rats received $0.9 \% \mathrm{NaCl}$ p.o. and the experimental rats received KTJ $(10 \mathrm{~mL} / \mathrm{kg}, 20 \mathrm{~mL} / \mathrm{kg}$, and $40 \mathrm{~mL} / \mathrm{kg}$ p.o.). Thirty minutes later, the rats were given a subcutaneous injection of $0.05 \mathrm{~mL}$ of $1 \%$ solution of carrageenan to the left hind paw.

\subsection{Dissociation between CNS and Peripheral Analgesic Activity \\ 2.7.1. Formalin induced Paw-licking test:}

The experimental mice were randomly assigned to six groups; each group had eight mice. The formalin test was conducted based on the method of Tjølsen et al. ${ }^{[13]}$. For the formalin test, groups of mice were treated p.o. with $\mathrm{NaCl}(0.9 \% \mathrm{w} / \mathrm{v})$ (for control), KTJ at three doses $(10 \mathrm{~mL} / \mathrm{kg}, 20 \mathrm{~mL} / \mathrm{kg}$, and $40 \mathrm{~mL} / \mathrm{kg}$ p.o.) (for treatment group), tramadol (10mg/Kg p.o.), and diclofenac $\mathrm{Na}(10 \mathrm{mg} / \mathrm{Kg}$ p.o.) (both for positive control). tramadol was used as the positive control drug for both nurogenic phase and inflammatory phases. diclofenac $\mathrm{Na}$ was used as the positive control drug for the later inflammatory phase.

Naloxone $(5 \mathrm{mg} / \mathrm{kg}$ i.p.) was administered with KTJ $(10 \mathrm{~mL} / \mathrm{kg}, 20 \mathrm{~mL} / \mathrm{kg}$, and $40 \mathrm{~mL} / \mathrm{kg}$ p.o.) and tramadol to four different groups, other than the treatment groups. Percentage inhibition was obtained by using this formula [14]:<smiles>O=[W][Te][Te]</smiles>

$\mathrm{T}_{0}=$ mean licking time for the control group

$\mathrm{T}_{\mathrm{t}}=$ mean licking time for the test group 
Investigation of the Central and Peripheral Analgesic and Anti-inflammatory Activity of kutajarishta 2.8 Acute toxicity study:

Doses of $5,10,15,20,30,50,75 \mathrm{ml} / \mathrm{Kg}$ of preparation were administered orally to mice. The preparation was given at the doses of 5 and $10 \mathrm{ml} / \mathrm{Kg}$ of body weight/day. All the animals were found to be safe at highest dose $(75 \mathrm{ml} / \mathrm{Kg})$. Then the mice were observed for incidence of mortality or any sign of toxicity up to 24 h. OECD Guideline (OECD Guideline 425) were followed in maintaining dosing schedule ${ }^{[15]}$.

\subsection{Statistical analysis:}

Results were expressed as mean \pm SEM (standard error of mean) of responses. All tests were done using SPSS Software Ver. 20. For Hot Plate test, Tail Immersion test, and Carrageenan induced Rat Paw Edema test, Statistical significance was determined by Repeated Measures One-way Analysis of Variance (ANOVA) followed by post hoc Dunnett test. Later, Pair-wise comparison test along with Bonferroni correction were done. For Acetic acid induced writhing test and Formalin test, Statistical significance was determined by One-way Analysis of Variance (ANOVA) followed by post hoc Dunnett test. Then Pair-wise comparison test along with Bonferroni correction were done. The $\mathrm{P}$ values less than 0.05 were considered to be significant.

\subsection{Hot-plate Test:}

\section{Result}

In the Hot Plate Test, KTJ treatment caused no significant increase in analgesia. In the presence of Naloxone, an antagonist of opioid receptor, the effect of tramadol was reduced profoundly as shown in TABLE 1.

\subsection{Tail Immersion Test:}

TABLE 2 shows that the analgesic effect of KTJ was also not significant in Tail immersion test. KTJ failed to induce any "tail flick antinociceptive" index.

\subsection{Acetic acid induced writhing test:}

Intraperitoneal injection of $0.7 \%$ acetic acid given to the control group caused $16.83 \pm 0.87$ writhes in a 5 minute interval. The treatment with KTJ induced a significant decrease, with a $53.48 \%(\mathrm{p}<0.05), 57.40 \%$ $(\mathrm{p}<0.01)$, and $77.24 \%(\mathrm{p}<0.01)$ inhibition observed in the 10,20 , and $40 \mathrm{~mL} / \mathrm{Kg}$ group respectively (Fig 1).

\subsection{Carrageenan induced Paw edema test:}

The injection of carrageenan at rat paw created an edema that increased gradually (TABLE 3). KTJ $20 \mathrm{~mL} / \mathrm{kg}$ showed $22.22 \%$ and $32.03 \%$ reduction in the volume of the edematous paw at $4 \mathrm{~h}$ and $5 \mathrm{~h}$ after carrageenan injection respectively. Whereas, KTJ $40 \mathrm{~mL} / \mathrm{Kg}$ showed significant anti-inflammatory activity starting from $2 \mathrm{~h}$ after the injection of carrageenan to throughout the experiment time with a highest reduction of $37.50 \%$ (5h after the carrageenan injection). KTJ $10 \mathrm{ml} / \mathrm{Kg}$ failed to produce any significant reduction.

\subsection{Formalin induced paw-licking Test:}

In the Formalin induced paw-licking test, KTJ treated mice groups except $10 \mathrm{~mL} / \mathrm{kg}$ group showed significant activities in the later phase pain responses $(20 \mathrm{~mL} / \mathrm{kg} 70.82 \%$ and $40 \mathrm{~mL} / \mathrm{kg} 86.18 \%)$ compared to that of the control group (TABLE 4). All three doses $(10 \mathrm{~mL} / \mathrm{kg}, 20 \mathrm{~mL} / \mathrm{kg}$, and $40 \mathrm{~mL} / \mathrm{kg}$ ) of KTJ failed to induce any significant analgesic activity at early phase of the experiment. In combination studies using Naloxone, an antagonist of opioid receptor, the analgesic activity of the tramadol was diminished in both phases. The analgesic activity of diclofenac $\mathrm{Na}$ was not diminished by the co-treatment with Naloxone. Co-treatment with naloxone also did not affect the analgesic activity of KTJ in the later phase of the experiment, suggesting that there might be no involvement of opioid receptor in the analgesic activity of KTJ.

\section{TABLE And FIGURE}

TABLE 1: Effect of KTJ on nociceptive responses in the Hot Plate Test

\begin{tabular}{|c|c|c|c|c|c|c|c|c|}
\hline \multirow[t]{2}{*}{ Group } & \multirow[t]{2}{*}{ Dose } & \multicolumn{7}{|c|}{ Latency Period (second) } \\
\hline & & $0 \min$ & $30 \min$ & $1 \mathrm{~h}$ & $2 \mathrm{~h}$ & $3 \mathrm{~h}$ & $4 h$ & $5 h$ \\
\hline Control & - & $10.40 \pm 0.3$ & $10.7 \pm 2.0$ & $10.6 \pm 2.2$ & $10.95 \pm 2.0$ & $10.96 \pm 2.0$ & $8.53 \pm 2.1$ & $9.22 \pm 1.98$ \\
\hline KTJ & $10 \mathrm{~mL} / \mathrm{Kg}$ & $9.78 \pm 0.6$ & $8.1 \pm 1.2$ & $7.3 \pm 1.3$ & $7.55 \pm 1.1$ & $9.17 \pm 1.6$ & $7.30 \pm 1.1$ & $6.60 \pm 1.00$ \\
\hline KTJ & $20 \mathrm{~mL} / \mathrm{Kg}$ & $8.30 \pm 0.7$ & $11.3 \pm 1.1$ & $11.1=1.2$ & $8.30 \pm 1.1$ & $9.13 \pm 1.3$ & $8.25 \pm 1.4$ & $5.77 \pm 0.93$ \\
\hline KTJ & $40 \mathrm{~mL} / \mathrm{Kg}$ & $7.83 \pm 0.6$ & $8.2 \pm 0.9$ & $8.3 \pm 1.3$ & $6.67 \pm 1.2$ & $6.78 \pm 1.6$ & $6.83 \pm 1.1$ & $5.18 \pm 1.05$ \\
\hline tramadol & $10 \mathrm{mg} / \mathrm{Kg}$ & $10.90=0.4$ & $18.6 \pm 2.3^{*}$ & $19.8 \pm 2.2 \div$ & $19.33 \pm 2.0 \pm$ & $19.13 \pm 2.1 \pm$ & $19.67 \pm 2.1 \pm$ & $19.78 \pm 1.98 \pm$ \\
\hline
\end{tabular}


Investigation of the Central and Peripheral Analgesic and Anti-inflammatory Activity of kutajarishta

\begin{tabular}{|c|c|c|c|c|c|c|}
\hline \multirow{2}{*}{$\begin{array}{l}\text { Treatment } \\
\text { Group }\end{array}$} & \multirow[t]{2}{*}{ Dose } & \multicolumn{5}{|c|}{ Latency Period (second) } \\
\hline & & $0 \min$ & $30 \mathrm{~min}$ & $60 \min$ & $90 \mathrm{~min}$ & $120 \mathrm{~min}$ \\
\hline Control & - & $7.33 \pm 1.81$ & $3.25 \pm 2.21$ & $4.92=2.91$ & $3.75 \pm 2.01$ & $3.83 \pm 2.59$ \\
\hline KTJ & $10 \mathrm{~mL} / \mathrm{Kg}$ & $3.17 \pm 2.10$ & $3.67 \pm 2.38$ & $3.17 \pm 2.39$ & $3.33 \pm 1.92$ & $4.42 \pm 1.96$ \\
\hline KTJ & $20 \mathrm{~mL} / \mathrm{Kg}$ & $3.33 \pm 2.07$ & $5.05 \pm 2.08$ & $4.45 \pm 2.43$ & $4.62 \pm 1.98$ & $3.13 \pm 2.03$ \\
\hline KTJ & $40 \mathrm{~mL} / \mathrm{Kg}$ & $4.50 \pm 2.01$ & $4.77 \pm 2.18$ & $4.33 \pm 2.07$ & $5.87 \pm 1.99$ & $5.47 \pm 2.08$ \\
\hline tramadol & $10 \mathrm{mg} / \mathrm{Kg}$ & $3.83 \pm 1.81$ & $21.83 \pm 2.21 \pm$ & $21.90 \pm 2.91 \pm$ & $20.33 \pm 2.01 \pm$ & $17.67 \pm 2.59 \pm$ \\
\hline
\end{tabular}

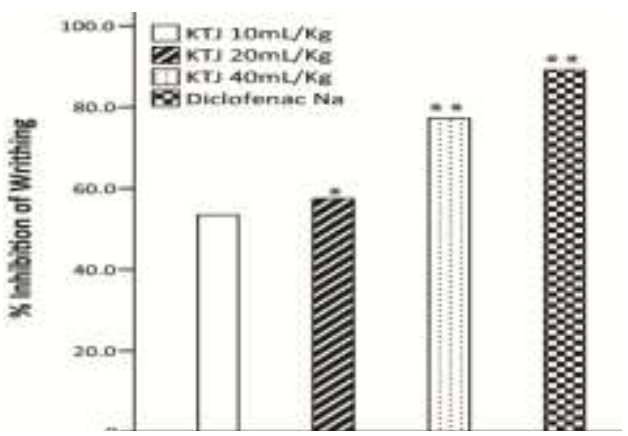

Figure 1: \% Inhibition of writhing in 5 min interval by KTJ $(10,20$, and $40 \mathrm{~mL} / \mathrm{kg})$ and Diclofenac $\mathrm{Na}$ in Acetic acid induced writhing test. $* \mathrm{p}<0.05$ and ${ }^{*} \mathrm{p}<0.01$ compared to the control group.

TABLE 3: Effect of KTJ on anti-inflammatory responses in Carrageenan induced rat paw edema rest.

\begin{tabular}{|c|c|c|c|c|c|c|c|c|}
\hline \multirow[t]{2}{*}{ Group } & \multirow[t]{2}{*}{ Dose } & \multicolumn{7}{|c|}{ Volume of Paw (ml) } \\
\hline & & $0 \mathrm{~min}$ & $30 \mathrm{~min}$ & $1 \mathrm{~h}$ & $2 \mathrm{~h}$ & $3 \mathrm{~h}$ & $4 \mathrm{~h}$ & $5 \mathrm{~h}$ \\
\hline Control & - & $0.77 \pm 0.01$ & $0.95 \pm 0.08$ & $1.01 \pm 0.07$ & $1.16 \pm 0.11$ & $1.17 \pm 0.08$ & $1.26 \pm 0.12$ & $1.28 \pm 0.13$ \\
\hline $\mathrm{KTJ}$ & $10 \mathrm{ml} / \mathrm{Kg}$ & $0.71 \pm 0.02$ & $0.92 \pm 0.03$ & $0.94 \pm 0.03$ & $1.05 \pm 0.10$ & $1.01 \pm 0.02$ & $1.09 \pm 0.11$ & $1.12 \pm 0.10$ \\
\hline KTJ & $20 \mathrm{ml} / \mathrm{Kg}$ & $0.74 \pm 0.04$ & $0.98 \pm 0.03$ & $0.92 \pm 0.02$ & $0.96 \pm 0.14$ & $0.95 \pm 0.09$ & $0.98 \pm 0.06^{*}$ & $0.87 \pm 0.05^{*}$ \\
\hline KTJ & $40 \mathrm{ml} / \mathrm{Kg}$ & $0.80 \pm 0.04$ & $1.01 \pm 0.06$ & $0.96 \pm 0.03$ & $0.90 \pm 0.10^{*}$ & $0.90 \pm 0.05^{*}$ & $0.89 \pm 0.07^{*}$ & $0.80 \pm 0.03 *$ \\
\hline $\begin{array}{l}\text { diclofenac } \\
\mathrm{Na}\end{array}$ & $10 \mathrm{mg} / \mathrm{Kg}$ & $0.76 \pm 0.05$ & $0.94 \pm 0.03$ & $0.95 \pm 0.21$ & $0.90 \pm 0.14^{*}$ & $0.89 \pm 0.11^{*}$ & $0.85 \pm 0.12^{*}$ & $0.78 \pm 0.09^{*}$ \\
\hline
\end{tabular}

TABLE 4: Effect of KTJ on nociceptive response in the Formalin Test.

\begin{tabular}{|c|c|c|c|c|c|}
\hline \multirow[t]{2}{*}{ Group } & \multirow[t]{2}{*}{ Dose } & \multicolumn{2}{|c|}{ Early Phase } & \multicolumn{2}{|c|}{ Later Phase } \\
\hline & & Licking time (s) & Inhibition $(\%)$ & Licking time (s) & Inhibition (\%) \\
\hline Control & - & $84.50 \pm 12.79$ & - & $43.42 \pm 13.50$ & - \\
\hline KTJ & $10 \mathrm{~mL} / \mathrm{Kg}$ & $83.67 \pm 2.50$ & 0.98 & $42.50 \pm 3.99$ & 2.49 \\
\hline KTJ & $20 \mathrm{~mL} / \mathrm{Kg}$ & $81.00 \pm 4.01$ & 4.14 & $12.67 \pm 0.88 *$ & $70.82 *$ \\
\hline KTJ & $40 \mathrm{~mL} / \mathrm{Kg}$ & $82.17 \pm 5.26$ & 2.76 & $6.00 \pm 0.93 \div$ & $86.18 \ddagger$ \\
\hline tramadol & $10 \mathrm{mg} / \mathrm{Kg}$ & $4.17 \pm 1.49 \ddagger$ & $95.07 \ddagger$ & $4.50 \pm 0.764 t$ & $89.64 t$ \\
\hline diclofenac $\mathrm{Na}$ & $10 \mathrm{mg} / \mathrm{Kg}$ & $62.50 \pm 8.65$ & 26.04 & $5.50 \pm 1.88 \ddagger$ & $87.33 \ddagger$ \\
\hline \multicolumn{6}{|c|}{ Co-treatment with naloxone } \\
\hline $\begin{array}{l}\text { KTJ + } \\
\text { Naloxone }\end{array}$ & $40 \mathrm{~mL} / \mathrm{Kg}$ & $80.17 \pm 4.85$ & 5.12 & $5.33 \pm 2.50 \ddagger$ & $87.72 \ddagger$ \\
\hline $\begin{array}{l}\text { tramadol + } \\
\text { Naloxone }\end{array}$ & $10 \mathrm{mg} / \mathrm{Kg}$ & $44.50 \pm 2.79$ & 47.34 & $23.17 \pm 1.38$ & 46.64 \\
\hline $\begin{array}{l}\text { diclofenac } \mathrm{Na}+ \\
\text { Naloxone }\end{array}$ & $10 \mathrm{mg} / \mathrm{Kg}$ & $71.83 \pm 5.87$ & 15.00 & $4.83 \pm 1.08 \ddagger$ & $88.88 \div$ \\
\hline
\end{tabular}

Values are expressed as Mean \pm S.E.M. Differences between groups are determined by One-Way ANOVA followed by post hoc Dunnett test. $* \mathrm{p}<0.05$ and $t \mathrm{p}<0.01$ compared to the control group.

\section{Discussion}

Two well known models of thermal nociception, hot-plate test and tail immersion test were employed to double check on possible involvement of spinal, supra-spinal pathways, and $\mu$-opiate receptor agonism in regulation (CNS modulation) of pain response by KTJ. Our findings demonstrated no activity of KTJ in either model. Hence, probable involvement of the central nervous system, in this case, could be ruled out. 

To reinforce the above findings, we employed the formalin induced paw-licking test. This test is capable of discerning between nurogenic pain (early phase, acute, non-inflammatory and CNS modulated) and inflammatory (chronic and peripheral pain) ${ }^{[16][17][18]}$. The neurogenic pain (first phase) is caused by direct chemical stimulation of nociceptive afferent fibers (predominantly $\mathrm{C}$ fibers) which can be suppressed by opiate like morphine ${ }^{[19]}$. The inflammatory pain (second phase) is caused by the release of inflammatory mediators like histamine, prostaglandins, bradykinin, serotonin in the peripheral tissues ${ }^{[18]}$, and from functional changes in the spinal dorsal horn ${ }^{[20]}$. Our results showed that KTJ had no effect on neurogenic pain suppression (first phase) but had effective anti-nociceptive effect in the peripheral inflammatory (second phase) pain. Cotreatment with naloxone partially blocked the activity of tramadol in both the phases while that of KTJ and diclofenac sodium remained unaffected. Hence, we have definitive evidence to conclude that KTJ has no CNS modulated pain suppression activity; however, probably has significant peripheral analgesic and antiinflammatory effect.

To further ascertain its anti-inflammatory activity, we performed the Acetic Acid induced writhing test and carrageenan induced paw edema test. Carrageenan induced edema is commonly used as an experimental model for acute inflammation, and is proven to be biphasic ${ }^{[18]}$. The early phase (1-2 hours) of the carrageenan model is chiefly mediated by serotonin and histamine release and increased synthesis of prostaglandins in the damaged paw tissues. These induce inflammation and paw swelling. The later phase is sustained by prostaglandin release and is also mediated by bradykinin, leukotrienes, poly-morphonuclear cells, and prostaglandins produced by tissue macrophages ${ }^{[21]}$. KTJ showed, in a dose dependent manner, significant peripheral analgesic activity at the end of the early phase ( $2 \mathrm{~h}$ ) and throughout the later phase indicating its possible ability to hinder endogenous synthesis or release of inflammatory mediators such as prostaglandins, histamine, serotonin, bradykinin and leukotrienes.

The acetic acid induced writhing test was carried out to confirm the peripheral analgesic activity of KTJ. The acetic acid used in this test increased the prostaglandin level (mainly $\mathrm{PGE}_{2}$ ) in the peritoneal fluid of the mice ${ }^{[22]}$. Prostaglandins induce abdominal constriction by activating and sensitizing the peripheral chemosensitive nociceptors which are mostly responsible for causing inflammatory pain [23]. In our study, KTJ, significantly attenuated the writhing in mice in response to IP acetic acid administration, albeit to a lesser extent compared to the highly potent diclofenac sodium. Hence, the analgesic and anti-inflammatory action of KTJ can be attributed to reduction of peripheral nociception by inhibition of prostaglandin release.

\section{Conclusion}

In summary, our present study has successfully elucidated the likely mechanism of anti-nociceptive and anti-inflammatory effect of Kutajarishta (KTJ). We have drawn a sound conclusion that KTJ does not have any CNS modulated effect in pain inhibition, based on three different in-vivo models. Its peripheral analgesic activity has been also repeatedly confirmed by three in-vivo models. Through this study, it is apparent that the mechanism of action of KTJ is similar to that of the commonly used NSAIDs. Hence, its traditional use in arthritis, sciatia, and lumbago held the test of time, not by its mere placebo effect but by some potent analgesic and anti-inflammatory molecules hidden in this age old Ayurvedic concoction. We believe that further studies are required to elucidate the complete pharmacological profile of this potential analgesic preparation for safer and more effective use.

\section{Acknowledgement}

The authors would like to thank Md. Mahmudul Hasan, Md. Rajib Ruhan, Dipan Kumar Kundu, Sayeda Hurmatul Quader (North South University) for their unwavering supports. Authors would also like to thank Mr. Fakruddin, Mrs. Junaida Khaleque, and Ms. Samina for providing the authors with full logistical support and giving sagacious advice.

[1]. WHO, Media Centre: Fact Sheet. [Online], December 2008, [Cited: May 18, 2012.] http://www.who.int/mediacentre/factsheets/fs134/en/.

[2]. Firenzuoli F. and Gor L., Herbal Medicine Today: Clinical and Research Issues, Evidence-Based Complementary and Alternative Medicine, 4, 2007, 37-40.

[3]. Tyler VE, Herbal medicine: from the past to the future, Public Health Nutrition, 3, 2000, 447-452.

[4]. Bonica JJ, The need of a Taxonomy, Pain 6, 1979, 247-252.

[5]. Bromm B and Lorenz J, Neurophysiological evaluation of Pain, Electroencephalography and Clinical Neurophysiology, 107, 1998, 227-25.

[6]. Park H, Cha D, Jeon H, Antinociceptive and hypnotic properties of Celastrus orbiculatus, Journal of Ethnopharmacology, 137, 2011, 1240-1244.

[7]. Bangladesh National Formulary of Ayurvedic Medicine 2011, $2^{\text {nd }}$ Ed (DGDA, Associates Printing Press, 2011).

[8]. Zimmerman M, Ethical guidelines for investigations of experimental pain in conscious animals, Pain 16, 1983, 109-110.

[9]. Franzotti EM, Santos CVF, Rodrigues HMSL, Mourão, CVF, Andrade MR, Antoniolli AR, Anti-inflammatory, analgesic activity and acute toxicity of Sida cordifolia L. (Malva-branca), Journal of Ethnopharmacology, 72, 2000, 273-277. 
[10]. Yang XY, Gao D, Pettus M, Phillips C, Bowersox SS, Interaction of intrathecally administered zinconotide, a selective blocker of neuronal N-type voltage- sensitive calcium channels, with morphone on nociception in rats, Pain, 84, 2000, $271-281$.

[11]. Praveen KSV, Sandeep M, Kamal D, Nishnth BC, Megharaj HK, Kekuda TRP, Gurucharan DN, Antibacterial and Anthelmintic activity of selected fermented Ayurvedic herbal formulations, Drug invention today, 2, 2010, 347-348.

[12]. Damas J, Volon GR, Influence of a long-acting bradykinin antagonist, Hoe 140, on some acute inflammatory reactios in the rat, European Journal of Pharmacology, 211, 1992, 81-86.

[13]. Tjølsen A, Berge OG, Hunskaar S, Rosland JH and Hole K, The formalin test: an evaluation of the method, Pain, 52, $1992,5-17$.

[14]. Chau TT, Analgesic testing in animal models, in Alan R, Pharmacological Methods in the Control of Inflammation (New York: Liss Inc, 1989) 195-212.

[15]. OECD Guideline (425) for the testing of chemicals, Guidance document on acute oral toxicity, Environmental Health and Safety Monograph Series on Testing and Assessmen, 2000.

[16]. Cowan A, Recent approaches in testing analgesics in animals, in Wiley, Modern Methods in Pharmacology (New York: Liss Inc, 1990) 33-42.

[17]. Agyare C, Kuffuor GA, Boamah VE, Adu F, Mensah KB, Adu-Amoah L, Antimicrobial and Anti-inflammatory Activities of Pterygota macrocarpa and Cola gigentea (Sterculiaceae), Evidence-Based Complementary and Alternative Medicine, 3, $2012,91-9$.

[18]. Amarlal JF, Silva MIG, Neto MRA, Neto PTF, Moura BA, Melo CTV, Araujo FLO, DeSousa DP, Vasconcelos PF, Vasconcelos SM, Sousa FCF, Antinociceptive effect of the monoterpene R-(-)-limonene in mice, Biological and Pharmaceutical Bulletin, 30, 2007, 1217-1220.

[19]. Dalal A, Tata M, Allegre G, Gekiere F, Bons N, Albe- Fessard D, Spontaneous activity of rat dorsal horn cells in spinal segments of sciatic projection following transcetions of sciatic nerve or of corresponding dorsal roots, Neuroscience, 94, 1999, $218-228$.

[20]. Brito AR, Antonio MA, Oral anti-inflammatory and anti-ulcerogenic activities of a hydroalcoholic extract and partitioned fractions of Turnera ulmifolia (Turneraceae), Journal of Ethnopharmacology, 61, 1998, 213-228.

[21]. Derardt R, Jougney S, Delevalcee F, Falhout M, Release of prostaglandins E and F in an algogenic reaction and its inhibition, European Journal of Pharmacology, 80, 1980, 17-24.

[22]. Dirig DM, Isakson PC, Yaksh TL, Effect of COX-1 and COX-2 inhibition on induction and maintainence of carrageenan-evoked thermal hyperalgesia in rats, The Journal of Pharmacology and Experimental Theraputics, 285, 1998, 1031-1038.

[23]. Bley KR, Hunter JC, Eglen RM, Smith JA, The role of IP prostanoid receptors in inflammatory pain, Trends in Pharmaoclogical Sciences, 19,1998, 141-147. 